\title{
Inter-Simple Sequence Repeat (ISSR) Polymorphism of Tuberculosis Patients from Mile Four Hospital, Abakaliki, Nigeria
}

\author{
Egesimba Ifeyinwa Gladys ${ }^{1,}$,, Ogah Fidelis ${ }^{1}$, Nnamani Catherine ${ }^{1}$, Afiukwa Celestine ${ }^{2}$, Igwe David ${ }^{2}$ \\ ${ }^{1}$ Department of Applied Biology, Faculty of Science, Ebonyi State University, Abakaliki, Nigeria \\ ${ }^{2}$ Department of Biotechnology, Faculty of Science, Ebonyi State University, Abakaliki, Nigeria
}

Email address:

ifeyinwaglad@gmail.com (E. I. Gladys)

*Corresponding author

To cite this article:

Egesimba Ifeyinwa Gladys, Ogah Fidelis, Nnamani Catherine, Afiukwa Celestine, Igwe David. Inter-Simple Sequence Repeat (ISSR) Polymorphism of Tuberculosis Patients from Mile Four Hospital, Abakaliki, Nigeria. International Journal of Homeopathy \& Natural Medicines. Vol. 6, No. 2, 2020, pp. 15-22. doi: 10.11648/j.ijhnm.20200602.12

Received: June 21, 2020; Accepted: July 15, 2020; Published: December 16, 2020

\begin{abstract}
Tuberculosis (TB) is a serious health issue in Ebonyi State and Nigeria at large. The knowledge of genetic diversity and population structure of TB patients in Ebonyi State is still inadequate. Therefore, this work tends to assess the genetic diversity and population structure in association with tuberculosis population using Inter-simple sequence repeat (ISSR) markers. A total of 25 samples were collected, in which 21 were from TB patients and 4 from NTB patients as controls. DNA extraction was done using Cetyltrimethylammonium bromide (CTAB) method followed by Polymerase chain reaction (PCR) with ISSR primers. Analyses of dendrogram, principal component analysis, genetic diversity and population structure were computed with the scored matrix data. Six ISSR markers were polymorphic. The polymorphic information content (PIC) values ranged from 0.2635 to 0.8158 with a mean of 0.6156 . The genetic diversity ranged from 0.1504 to 0.8352 with a mean of 0.6156 , while the major allele frequency ranged from 0.2800 to 0.9200 with a mean of 0.5018 . The allele count ranged from 1 to 23 , while the frequency ranged from 0.0400 to 0.9200 . The values of number of alleles $(\mathrm{Na})$, effective number of alleles $(\mathrm{Ne})$, Nei's gene diversity $(\mathrm{H})$ and Shannon's information index (I) from the entire population were $2.000 \pm 0.000$, $1.8562 \pm 0.1011,0.4595 \pm 0.0330$ and $0.6517 \pm 0.0350$, respectively while that of the six ISSR markers ranges from 1.3200 $2.0000,1.1184-1.9091,0.0456-0.4571$ and $0.1388-0.6611$, respectively. From the six ISSR marker data, the number of polymorphic loci (NPL) and percentage polymorphic loci (PPL) ranged from 2 to 25 and $32 \%$ to $100 \%$ respectively. A dendrogram of the $25 \mathrm{~TB}$ and non- NTB clustered them into nine major groups. This study revealed high diversity among TB patientsatgene loci also probed, but did not show any clear association between TB susceptibility and the gene loci.
\end{abstract}

Keywords: Polymorphic, Population Structure, Genetic Diversity, ISSR Markers, Dendrogram, Association

\section{Introduction}

Over the years, tuberculosis (TB) has remained a major public health problem both in Nigeria and the world at large. It has been an unprecedented world's most infectious deadly killer disease with about 4500 lives lost per day. Unfortunately, Nigeria is far worse hit by this global epidemic in Africa. Currently she ranks seventh in the world and second in Africa [1].

Tuberculosis is a chronic infectious disease; a pathogenic bacterial disease that is caused by a rod-shaped bacterium Mycobacterium tuberculosis [2]. This bacterium especially
Mycobacterium bovis or Bovis tuberculosis affects human beings and other higher animals like cattle [2]. The followings are the predisposing or risk factors of tuberculosis: HIV infection, malnutrition, alcoholism, silicosis, cigarette smoking, diabetes melittus, corticosteroids, infliximab, overcrowding and genetic susceptibility [3-6].

In the developing world Tuberculosis is a serious health issue, its etiological mechanisms is not clear and this hinders the development of effective strategies for the treatment of the disease. The worldwide resurgence of TB has been a very big challenge for health institutions and researchers over the 
years. According to World Health Organization (WHO) report in 2014, 8.6 million people developed TB disease while 1.3 million people died from TB disease as at 2012 and in this as many as 450,000 new TB cases were caused by multi drug resistant Mycobacterium tuberculosis strain and some are being caused by total drug resistant [7]. They also estimated that up to two billion individual are currently infected with TB [8]. The WHO global TB report in 2015 reveals that $\mathrm{TB}$ is responsible for the deaths of 1.5 million people and generated 10.4 million cases of which 100,000 were drug resistant tuberculosis [9]. In 2017, about 10 million people developed TB in 2017, there were 1.6 million deaths which among them were 300,000 HIV positive people, out of this 10 million people who fell ill with TB in 2017, only 6.4 million were officially recorded by national reporting systems, leaving 3.6 million people undiagnosed or detected but not reported [8]. Houben and Dodd in their work "The Global Burden of latent TB" reported that almost one in four people in the world are infected with TB bacteria [10]. In 2017, WHO reported that Nigeria is among the three countries that topped most in TB incidence [1].

Despite significant progress over the last decades, TB remains the world's deadliest infectious disease and requires acceleration of efforts to end its epidemic in Nigeria and the whole world. Although it is curable, some of the bacterium that causes TB is becoming resistant to TB drugs, Patients adherence to therapy is another difficult task because most regimes require taking the drug daily for six months even to two years for complicated cases. Because of this mismanagement of TB drugs which causes resistant to the main drugs, there may be a future TB epidemic with restricted treatment options, it is vital that TB control be managed properly and new tools developed to prevent, treat and diagnose the disease. Therefore an association study of candidates with TB need to be conducted so as to examine the association of predicted genetic materials with TB infections to allow identification of the gene for its susceptibility which could pave way to developing a protocol for suppressing the gene.

\section{Materials and Method}

\subsection{Study Area}

The research was carried out at the TB unit of Mile Four Hospital (MFH) Abakaliki, Ebonyi State, Nigeria. Mile Four Hospital is located in Abakaliki, Ebonyi State Nigeria at latitude $6.3^{0} 1^{1} \mathrm{~N}$ and longitude $8.1^{0} 3^{1} \mathrm{E}$. Other units in Mile Four Hospital includes; Leprosy Unit, Gynaecology Unit, Peadiatrics and General medicine unit. The patients in this hospital came from Ebonyi, Enugu, Abia and Anambra states.

\subsubsection{Experimental Design}

This study was designed to assess the genetic diversity of Tuberculosis patients using Inter-simple sequence repeat markers. Both TB patients' blood and the blood of people that are not with active TB were used. The study population includes a total of 25 individuals (21 TB patients and 4 non TB patients).

\subsubsection{Ethical Consideration}

Ethical clearance was collected from Ebonyi state University with reference number EBSU/DRIC/UREC/VOL. 04/056 and mile four hospital. Written informed consent was obtained from all participants who willingly accepted to participate in the study.

\subsection{Sample Collection and Analysis}

Five millilitres of blood sample were collected by the nurses in the hospital through vein puncture from each consenting individual into a sterile container with ethyldiamine-tetraacetric acid (EDTA) anticoagulants. Each sample was labeled with the date of collection and laboratory identity number. Samples were transported to the laboratory immediately in cold box with frozen ice packs to achieve condition of about $4-8^{\circ} \mathrm{C}$. The molecular analysis was carried out in Biotech Research Centre in Ebonyi State University, Abakaliki, Ebonyi State, Nigeria.

\subsubsection{Analysis of Genetic Diversity Using ISSR Marker Techniques}

Genomic DNA was extracted from blood samples of 21TB patients and 4 Non TB individuals using CTAB method of DNA extraction procedure. From the blood sample, $250 \mu \mathrm{L}$ of whole blood was pipetted and $3 \mathrm{ml}$ of whole blood was also pipetted, $500 \mu \mathrm{L}$ of extraction buffer was added in a sterile $1.5 \mathrm{ml}$ microcentrifuge, It was thoroughly mixed and vortexed. Then it was incubated in water bath at $60^{\circ} \mathrm{C}$ for 15 minutes, brought to room temperature and equal volume of phenol was added, chloroform and iso-amyl alcohol was also added in the ratio of 25:24:1. It was well mixed by vortexing and centrifuged at $13000 \mathrm{rpm}$ for $10 \mathrm{~min}$. It then was removed from the centrifuge and $450 \mathrm{ul}$ of the supernatant was transferred into new sterile $1.5 \mathrm{ml}$ tube. $400 \mu \mathrm{L}$ of ice-cold isopropanol was added for precipitation of the DNA and it was mixed and incubated for 2 hours at $-20^{\circ} \mathrm{C}$. After the incubation, it was transferred to the centrifuging machine and centrifuged at $14000 \mathrm{rpm}$ for $15 \mathrm{~min}$ to sediment the DNA. The supernatant was decanted gently ensuring that the pellets were not disturbed. $500 \mathrm{~s} \mu \mathrm{L}$ of $70 \%$ ethanol was added to the pellets and centrifuged at $13000 \mathrm{rpm}$ for 5 min to wash the pellet. The ethanol was decanted and airdried the DNA at room temperature. The pellets were suspended in $100 \mu \mathrm{l}$ of nuclease free water for further use or storage.

DNA quality was assessed by using $1.5 \%$ agarose gel for electrophoresis. It was then visualized under UV light.

\subsubsection{PCR Amplifications}

PCR amplification was done using PCR machine and ISSR makers

The PCR consisted of $2.0 \mu \mathrm{L}$ of $100 \mathrm{ng} / \mu \mathrm{L}$ DNA, $2.5 \mu \mathrm{L}$ of $10 \mathrm{x}$ buffer (Bioline, Taunton, USA), $1.5 \mu \mathrm{L}$ of $50 \mathrm{mM} \mathrm{MgCl}_{2}$ (Bioline, Taunton, USA), $2.0 \mu \mathrm{L}$ of $2.5 \mathrm{mMdNTPs}$ (Bioline, Taunton, USA), and $0.2 \mu \mathrm{L} 500 \mathrm{U}$ DNA Taq polymerase (Bioline, Taunton, USA), $1.0 \mu \mathrm{L}$ of $10 \mathrm{ppm}$ each primer per ISSR primer and was made up to total volume of $25 \mathrm{uL}$ by adding 15.8 $\mu \mathrm{L}$ DEPC-treated water (Invitrogen Corporation, USA). The PCR cycling profile for the reaction consist of an initial step at $94^{\circ} \mathrm{C}$ for $5 \mathrm{~min}$., 35 cycles of $94^{\circ} \mathrm{C}$ for $30 \mathrm{~s}$, 
$55^{\circ} \mathrm{C}$ for $1 \mathrm{~min}$, and $72^{\circ} \mathrm{C}$ for $1 \mathrm{~min}$., and 8 -min final extension at $72^{\circ} \mathrm{C} .5 \mu \mathrm{L}$ of the amplicon was electrophoresed in $1.5 \%$ agarose gel containing $0.5 \mathrm{mg} / \mathrm{ml}$ ethidium bromide.

Gel electrophoresis was done using agarose gel and electrophoresis apparatus while the image was viewed and captured using transilluminator UV light. 1.5\% Agarose Gel was prepared using Biology dictionary.net/gel electrophoresis method. The following buffers and solutions were used; Agarose solution, Ethidium bromide and electrophoresis buffer and DNA samples and ladders were used for the nucleic acids and oligonucleotides.

Table 1. List of primers used for this study.

\begin{tabular}{lll}
\hline S/N & Primer name & Sequence (5'-3') \\
\hline 1. & ISSR889 & D $^{\mathrm{c}} \mathrm{B}^{\mathrm{d}} \mathrm{D}^{\mathrm{c}}$ ACA CAC ACACAC AC \\
2. & ISSR827 & ACACACACACACACACG \\
3. & ISSR856 & ACACACACACACACACY ${ }^{\mathrm{a}}$ \\
4. & UBC826 & ACACACACACACACACC \\
5. & ISSR888 & BDB CAC ACA CACACACA \\
6. & ISSR816 & CACACACACACACACAT \\
7. & ISSR890 & VHVGTGTGTGTGTGTGT \\
8. & ISSR836 & AGA GAG AGA GAG AGA GY \\
9. & ISSR901 & CACACACACACACACARY \\
10. & ISSR808 & AGAGAGAGAGAGAGAGC \\
ISSR Data & & \\
Analysis & & \\
\hline
\end{tabular}

The ISSR data was analyzed by scoring one (presence of alleles) and $\mathrm{O}$ (absence of alleles). The data achieved from the scoring of the ISSR amplicons were used for phylogenetic reconstruction using Unweighted Pair Group Mean Arithmetic (UPGMA) and dissimilarity index in Jaccard's option (Jaccard, 1908) were used for the analysis. The analysis was conducted using NTSYSpc software version 2.02.

The genetic diversity, allele frequency and PIC were computed using Power Marker (Version 3.25). Genetic diversity and population structure analyses of the accessions were analyzed using POPGENE software version 1.32.

\section{Results}

\subsection{ISSR Polymorphism}

To access the level of genetic diversity in 25 samples of TB and NTB population studied, a total of ten ISSR primers were used to study the genetic diversity among the human population identified to be TB and non-TB individuals. The ten primers produced bands that were used in the analyses. The ten (10) ISSR primers amplified a total of 155 alleles. The amplified alleles from each primer ranged from 3-24, with a mean of 15.500 (Table 2). Polymorphic information content values ranged from $0.1450-0.8158$ with a mean value of 0.5872 . The ISSR markers such as ISSR $889,827,856,826$, 890 , and 901 were found to be polymorphic while ISSR 888 , 816,836 and 808 were monomorphic with the least of PIC values. The genetic diversity ranged from $0.1504-0.8352$ with a mean value of 0.6156 while major allele frequency spanned from $0.2800-0.9200$ with a mean value of 0.5018 .

Table 2. Allele frequency, number of alleles, gene diversity and polymorphic information content values generated from twenty five $T B$ and Non $T B$ patients using ten ISSR markers.

\begin{tabular}{llllll}
\hline Marker & $\begin{array}{l}\text { Major allele } \\
\text { frequency }\end{array}$ & $\begin{array}{l}\text { No. of } \\
\text { obs. }\end{array}$ & Allele No & $\begin{array}{l}\text { Gene } \\
\text { diversity }\end{array}$ & PIC \\
\hline ISSR 889 & 0.4000 & 25.0000 & 24.0000 & 0.7392 & 0.7010 \\
ISSR 827 & 0.6000 & 25.0000 & 23.0000 & 0.5952 & 0.5618 \\
ISSR 856 & 0.3600 & 25.0000 & 24.0000 & 0.7872 & 0.7623 \\
UBC 826 & 0.2800 & 25.0000 & 24.0000 & 0.8352 & 0.8158 \\
ISSR 888 & 0.8400 & 25.0000 & 3.0000 & 0.2816 & 0.2635 \\
ISSR 816 & 0.7600 & 25.0000 & 3.0000 & 0.3904 & 0.3531 \\
ISSR 890 & 0.3600 & 25.0000 & 22.0000 & 0.7808 & 0.7521 \\
ISSR 836 & 0.9200 & 25.0000 & 10.0000 & 0.1504 & 0.1450 \\
ISSR 901 & 0.2800 & 25.0000 & 18.0000 & 0.7936 & 0.7625 \\
ISSR 808 & 0.6800 & 25.0000 & 4.0000 & 0.4576 & 0.3834 \\
Mean & 0.5018 & 25.0000 & 15.500 & 0.6156 & 0.5872 \\
\hline
\end{tabular}

$\mathrm{PIC}=$ Polymorphic information content

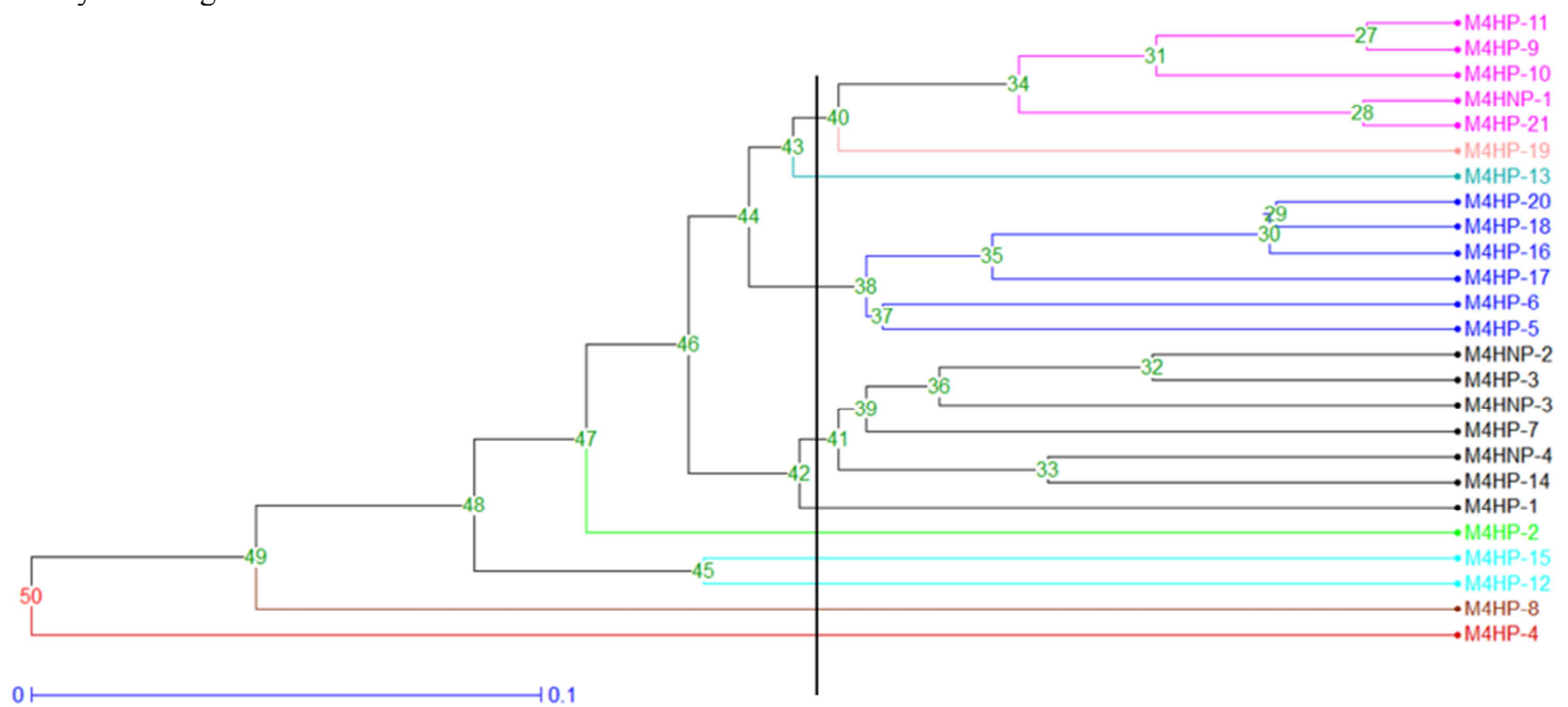

Similarity level at $42 \%$

Figure 1. Dendrogram of tuberculosis and non-tuberculosis populations as determined by ten Inter-simple sequence repeat (ISSR) markers. 


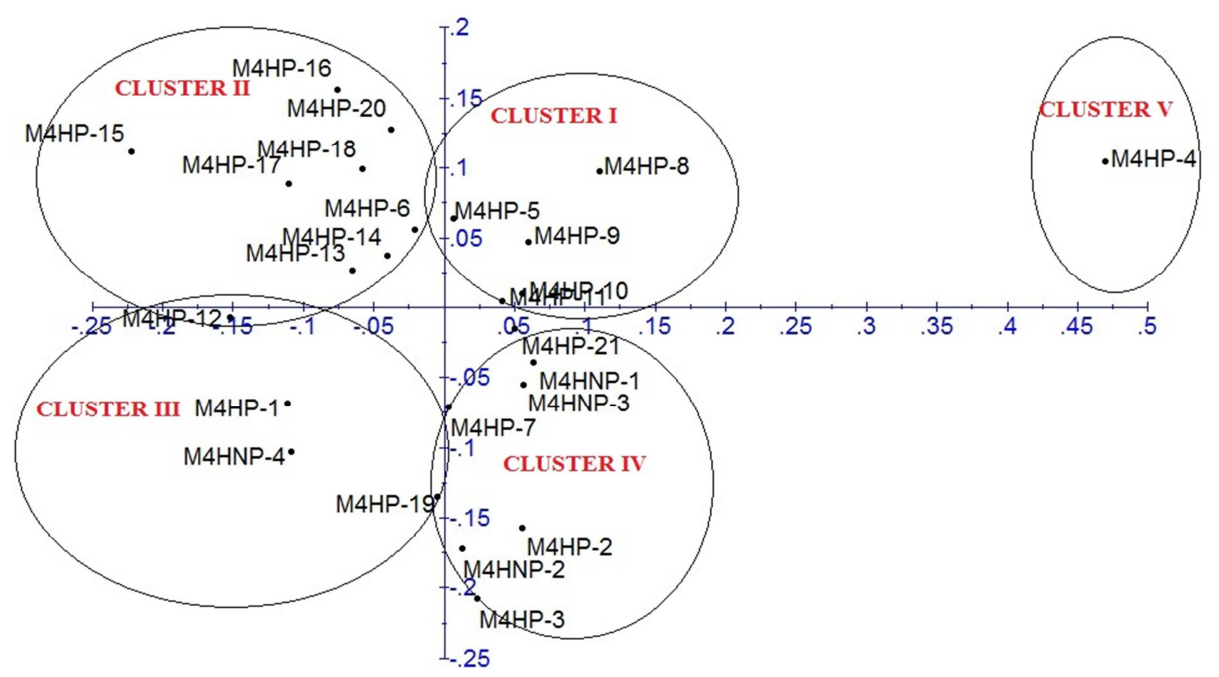

Figure 2. Principal component analysis of tuberculosis and non-tuberculosis patients as revealed by ten inter-simple sequence repeat markers.

Table 3 represented the allele, allele count and frequency obtained from each of the ISSR loci in the genotypes. The allele count spanned between 1 and 23 while the frequency ranged from 0.0400 and 0.9200 .

The ISSR markers revealed the highest genetic diversity in the TB sample from Enugu State population compared to the other populations, with number of alleles $(\mathrm{Na})$, effective number of alleles (Ne), Nei's gene diversity $(\mathrm{H})$, and Shannon's information index (I) values of 2.000, 1.9007, 0.4739 and 0.6668 , respectively with a sample size of 1 (Table 4), while the genetic diversity in Anambra State population was found to be the lowest, with corresponding values of $2.000,1.8207,0.4455$ and 0.6363 . The degree of genetic diversity of these samples were ranked in a decreasing order as Enugu $>$ Ebonyi $>$ Abia $>$ Anambra populations. From the ISSR markers, the mean values of Na, $\mathrm{Ne}, \mathrm{H}$ and I from the entire population were $2.000,1.8562$, 0.4595 and 0.6517 with standard deviations of $0.000,0.1011$, 0.0330 and 0.0350 , respectively.

Table 3. Allele, allele count and frequency values generated from twenty five Tuberculosis and NON Tuberculosis patients using ten Inter Simple Sequence Repeat markers.

\begin{tabular}{llll}
\hline Marker & Allele & Count & Frequency \\
\hline ISSR 889 & $0 / 0 / 0 / 1$ & 1 & 0.0400 \\
ISSR 889 & $0 / 0 / 1 / 0$ & 4 & 0.1600 \\
ISSR 889 & $0 / 0 / 1 / 1$ & 6 & 0.2400 \\
ISSR 889 & $0 / 1 / 1 / 0$ & 10 & 0.4000 \\
ISSR 889 & $0 / 1 / 1 / 1$ & 3 & 0.1200 \\
ISSR 889 & $1 / 1 / 1 / 0$ & 1 & 0.0400 \\
ISSR 827 & $0 / 1 / 1 / 0 / 0 / 1 / 0$ & 4 & 0.1600 \\
ISSR 827 & $0 / 1 / 1 / 1 / 0 / 1 / 0$ & 15 & 0.6000 \\
ISSR 827 & $0 / 1 / 1 / 1 / 0 / 1 / 1$ & 1 & 0.0400 \\
ISSR 827 & $0 / 1 / 1 / 1 / 1 / 1 / 0$ & 3 & 0.1200 \\
ISSR 827 & $1 / 1 / 1 / 1 / 0 / 1 / 0$ & 1 & 0.0400 \\
ISSR 827 & $1 / 1 / 1 / 1 / 1 / 1 / 0$ & 1 & 0.0400 \\
ISSR 856 & $0 / 0 / 0 / 0 / 1$ & 1 & 0.0400 \\
ISSR 856 & $0 / 0 / 1 / 0 / 0$ & 6 & 0.2400 \\
ISSR 856 & $0 / 0 / 1 / 1 / 1$ & 1 & 0.0400 \\
ISSR 856 & $0 / 1 / 1 / 0 / 1$ & 3 & 0.1200 \\
ISSR 856 & $0 / 1 / 1 / 1 / 0$ & 1 & 0.0400 \\
ISSR 856 & $1 / 0 / 1 / 0 / 1$ & 1 & 0.0400 \\
\hline
\end{tabular}

\begin{tabular}{llll}
\hline Marker & Allele & Count & Frequency \\
\hline ISSR 856 & $1 / 1 / 1 / 0 / 1$ & 1 & 0.0400 \\
ISSR 856 & $1 / 1 / 1 / 1 / 0$ & 1 & 0.0400 \\
ISSR 856 & $1 / 1 / 1 / 1 / 1$ & 1 & 0.0400 \\
UBC 826 & $0 / 0 / 0 / 0 / 1$ & 2 & 0.0800 \\
UBC 826 & $0 / 0 / 1 / 0 / 1$ & 2 & 0.0800 \\
UBC 826 & $0 / 0 / 1 / 1 / 1$ & 2 & 0.0800 \\
UBC 826 & $0 / 1 / 1 / 0 / 1$ & 3 & 0.1200 \\
UBC 826 & $0 / 1 / 1 / 1 / 1$ & 4 & 0.1600 \\
UBC 826 & $1 / 0 / 1 / 1 / 1$ & 1 & 0.0400 \\
UBC 826 & $1 / 1 / 1 / 0 / 1$ & 7 & 0.2800 \\
UBC 826 & $1 / 1 / 1 / 1 / 1$ & 4 & 0.1600 \\
ISSR 888 & $0 / 0 / 0 / 1$ & 2 & 0.0800 \\
ISSR 888 & $1 / 1 / 0 / 1$ & 2 & 0.0800 \\
ISSR 888 & $1 / 1 / 1 / 1$ & 21 & 0.8400 \\
ISSR 816 & $0 / 0 / 1$ & 2 & 0.0800 \\
ISSR 816 & $0 / 1 / 1$ & 4 & 0.1600 \\
ISSR 816 & $1 / 1 / 1$ & 19 & 0.7600 \\
ISSR 890 & $1 / 0 / 0 / 0$ & 5 & 0.2000 \\
ISSR 890 & $1 / 0 / 0 / 1$ & 3 & 0.1200 \\
ISSR 890 & $1 / 0 / 1 / 0$ & 2 & 0.0800 \\
ISSR 890 & $1 / 1 / 0 / 0$ & 1 & 0.0400 \\
ISSR 890 & $1 / 1 / 0 / 1$ & 4 & 0.1600 \\
ISSR 890 & $1 / 1 / 1 / 1$ & 9 & 0.3600 \\
ISSR 836 & $0 / 0 / 0$ & 1 & 0.0400 \\
ISSR 836 & $0 / 1 / 1$ & 23 & 0.9200 \\
ISSR 836 & $1 / 1 / 1$ & 1 & 0.0400 \\
ISSR 901 & $0 / 0 / 0$ & 3 & 0.1200 \\
ISSR 901 & $0 / 1 / 0$ & 5 & 0.2000 \\
ISSR 901 & $0 / 1 / 1$ & 3 & 0.1200 \\
ISSR 901 & $1 / 0 / 0$ & 1 & 0.0400 \\
ISSR 901 & $1 / 1 / 0$ & 7 & 0.2800 \\
ISSR 901 & $1 / 1 / 1$ & 6 & 0.2400 \\
ISSR 808 & $0 / 0$ & 17 & 0.6800 \\
ISSR 808 & $1 / 0$ & 7 & 0.2800 \\
ISSR 808 & $1 / 1$ & 1 & 0.0400 \\
\hline & & & \\
\hline
\end{tabular}

Population Structure and Genetic Diversity of TB Population from Mile Four Hospital Abakaliki

From the genetic differentiation using ISSR markers, the mean values of total gene diversity $(\mathrm{Ht})$, gene diversity within population (Hs), coefficient of gene differentiation or gene diversity among the population (Gst) and level of gene flow $(\mathrm{Nm})$ were $0.4515,0.3869,0.1580$ and 2.6647, respectively. This is shown in Table 5. The values of Ht, Hs, 
Gst and Nm from the sample collected from patients from Enugu State ranged from 0.000-0.4739, 0.000-0.4000, 0.0000-0.1559 and 0.0000-2.7072 with mean values of $0.4739,0.4000,0.1559$ and 2.7072 , respectively. The values of Ht, Hs, Gst and Nm from the population of TB and NTB collected from patients from Ebonyi State ranged from $0.4506-0.4898,0.3429-0.4327,0.0578-0.2533$ and $1.4737-$ 8.1538 with mean values of $0.4634,0.3899,0.1582$ and 3.0452, respectively. Those collected from patients from
Anambra State had the values of $\mathrm{Ht}, \mathrm{Hs}$, Gst and $\mathrm{Nm}$ from the population ranged from $0.3367-0.4800,0.2857-0.4408$, $0.0816-0.1837$ and $2.2222-5.6250$ with mean values of $0.4455,0.3853,0.1368$ and 1.0373 , respectively. Those collected from patients from Abia State had the values of $\mathrm{Ht}$, $\mathrm{Hs}$, Gst and $\mathrm{Nm}$ from the population ranged from $0.4200-$ $0.4898,0.3102-0.4082,0.1667-0.2614$ and $1.4126-2.5000$ with mean values of $0.4549,0.3592,0.2141$ and 1.9563, respectively.

Table 4. Genetic diversity parameters generated from 25 samples from Tuberculosis and Non-Tuberculosis patients using ten ISSR markers.

\begin{tabular}{|c|c|c|c|c|c|c|}
\hline Sample name & Location & Population size & $\mathrm{Na}$ & $\mathrm{Ne}$ & $\mathbf{H}$ & I \\
\hline M4HP-1 & Ebonyi & \multirow[t]{20}{*}{17} & 2 & 1.8491 & 0.4592 & 0.6518 \\
\hline M4HP-2 & Ebonyi & & 2 & 1.6897 & 0.4082 & 0.5983 \\
\hline M4HP-3 & Ebonyi & & 2 & 1.7896 & 0.4412 & 0.6332 \\
\hline M4HP-5 & Ebonyi & & 2 & 1.9429 & 0.4853 & 0.6784 \\
\hline M4HP-6 & Ebonyi & & 2 & 1.876 & 0.4669 & 0.6597 \\
\hline M4HP-7 & Ebonyi & & 2 & 1.9429 & 0.4853 & 0.6784 \\
\hline M4HP-8 & Ebonyi & & 2 & 1.8202 & 0.4506 & 0.6429 \\
\hline M4HP-11 & Ebonyi & & 2 & 1.9007 & 0.4739 & 0.6668 \\
\hline M4HP-13 & Ebonyi & & 2 & 1.96 & 0.4898 & 0.6829 \\
\hline M4HP-15 & Ebonyi & & 2 & 1.8491 & 0.4592 & 0.6518 \\
\hline M4HP-16 & Ebonyi & & 2 & 1.8491 & 0.4592 & 0.6518 \\
\hline M4HP-18 & Ebonyi & & 2 & 1.9007 & 0.4739 & 0.6668 \\
\hline M4HP-21 & Ebonyi & & 2 & 1.9007 & 0.4739 & 0.6668 \\
\hline M4HNP-1 & Ebonyi & & 2 & 1.876 & 0.4669 & 0.6597 \\
\hline M4HNP-2 & Ebonyi & & 2 & 1.8202 & 0.4506 & 0.6429 \\
\hline M4HNP-3 & Ebonyi & & 2 & 1.8491 & 0.4592 & 0.6518 \\
\hline M4HNP-4 & Ebonyi & & 2 & 1.9007 & 0.4739 & 0.6668 \\
\hline Total & & & 34 & 31.7167 & 7.8772 & 11.1508 \\
\hline \multirow[t]{2}{*}{ Mean } & & & 2 & 1.8657 & 0.4634 & 0.6560 \\
\hline & & & & $\mathrm{Ne}$ & $\mathrm{H}$ & I \\
\hline M4HP-4 & Anambra & 5 & 2 & 1.5077 & 0.3367 & 0.5196 \\
\hline M4HP-9 & Anambra & & 2 & 1.9231 & 0.48 & 0.673 \\
\hline M4HP-10 & Anambra & & 2 & 1.9231 & 0.48 & 0.673 \\
\hline M4HP-14 & Anambra & & 2 & 1.96 & 0.4898 & 0.6829 \\
\hline M4HP-19 & Anambra & & 2 & 1.7896 & 0.4412 & 0.6332 \\
\hline Total & & & 10 & 9.1035 & 2.2277 & 3.1817 \\
\hline Mean & & & 2 & 1.8207 & 0.4455 & 0.6363 \\
\hline M4HP-20 & Enugu & 1 & 2 & 1.9007 & 0.4739 & 0.6668 \\
\hline Total & & & 2 & 1.9007 & 0.4739 & 0.6668 \\
\hline Mean & & & 2 & 1.9007 & 0.4739 & 0.6668 \\
\hline M4HP-12 & Abia & 2 & 2 & 1.7241 & 0.42 & 0.6109 \\
\hline M4HP-17 & Abia & & 2 & 1.96 & 0.4898 & 0.6829 \\
\hline Total & & & 4 & 3.6841 & 0.9098 & 1.2938 \\
\hline
\end{tabular}

Table 5. Genetic differentiation in the populations of TB and Non-TB patients using ten ISSR markers.

\begin{tabular}{|c|c|c|c|c|c|c|}
\hline Sample name & Location & Population size & $\mathrm{Ht}$ & Hs & Gst & $\mathrm{Nm}$ \\
\hline M4HP-1 & Ebonyi & 17 & 0.4592 & 0.3673 & 0.2000 & 2.0000 \\
\hline M4HP-2 & Ebonyi & & 0.4082 & 0.3592 & 0.1200 & 3.6667 \\
\hline M4HP-3 & Ebonyi & & 0.4412 & 0.3837 & 0.1304 & 3.3333 \\
\hline M4HP-5 & Ebonyi & & 0.4853 & 0.4000 & 0.1758 & 2.3445 \\
\hline M4HP-6 & Ebonyi & & 0.4669 & 0.4000 & 0.1434 & 2.9878 \\
\hline M4HP-7 & Ebonyi & & 0.4853 & 0.4245 & 0.1253 & 3.4899 \\
\hline M4HP-8 & Ebonyi & & 0.4506 & 0.3592 & 0.2029 & 1.9643 \\
\hline M4HP-11 & Ebonyi & & 0.4739 & 0.3918 & 0.1731 & 2.3881 \\
\hline M4HP-13 & Ebonyi & & 0.4898 & 0.4163 & 0.1500 & 2.8333 \\
\hline M4HP-15 & Ebonyi & & 0.4592 & 0.3429 & 0.2533 & 1.4737 \\
\hline M4HP-16 & Ebonyi & & 0.4592 & 0.3592 & 0.2178 & 1.7959 \\
\hline M4HP-18 & Ebonyi & & 0.4739 & 0.3837 & 0.1904 & 2.1267 \\
\hline M4HP-21 & Ebonyi & & 0.4739 & 0.4000 & 0.1559 & 2.7072 \\
\hline M4HNP-1 & Ebonyi & & 0.4669 & 0.4000 & 0.1434 & 2.9878 \\
\hline M4HNP-2 & Ebonyi & & 0.4506 & 0.4082 & 0.0942 & 4.8077 \\
\hline M4HNP-3 & Ebonyi & & 0.4592 & 0.4327 & 0.0578 & 8.1538 \\
\hline M4HNP-4 & Ebonyi & & 0.4739 & 0.4000 & 0.1559 & 2.7072 \\
\hline
\end{tabular}




\begin{tabular}{lllllll}
\hline Sample name & Location & Population size & Ht & Hs & Gst & Nm \\
\hline Total & & & 7.8772 & 6.6287 & 2.6896 & 51.7679 \\
Mean & & 0.4634 & 0.3899 & 0.1582 & 3.0452 \\
Sample name & Location & Population size & Ht & Hs & Gst & Nm \\
M4HP-4 & Anambra & 5 & 0.3367 & 0.2857 & 0.1515 & 2.8000 \\
M4HP-9 & Anambra & & 0.4800 & 0.3918 & 0.1837 & 2.2222 \\
M4HP-10 & Anambra & & 0.4800 & 0.4408 & 0.0816 & 5.6250 \\
M4HP-14 & Anambra & & 0.4898 & 0.4408 & 0.1000 & 4.5000 \\
M4HP-19 & Anambra & & 0.4412 & 0.3673 & 0.1674 & 2.4862 \\
Total & & 2.2277 & 1.9264 & 0.6842 & 17.6334 \\
Mean & & & 0.4455 & 0.3853 & 0.1368 & 1.0373 \\
M4HP-20 & Enugu & 1 & 0.4739 & 0.4 & 0.1559 & 2.7072 \\
Total & & & 0.4739 & 0.4 & 0.1559 & 2.7072 \\
Mean & & 0.4739 & 0.4 & 0.1559 & 2.7072 \\
M4HP-12 & Abia & 2 & 0.4200 & 0.3102 & 0.2614 & 1.4126 \\
M4HP-17 & Abia & & 0.4898 & 0.4082 & 0.1667 & 2.5000 \\
Total & & 0.9098 & 0.7184 & 0.4281 & 3.9126 \\
Mean & & 0.4549 & 0.3592 & 0.2141 & 1.9563 \\
Over all mean & & 0.4595 & 0.3869 & 0.158 & 2.6647 \\
St. Dev & & 0.0011 & 0.0014 & \\
\hline
\end{tabular}

$\mathrm{Ht}=$ total gene diversity; $\mathrm{Hs}=$ gene diversity within population; $\mathrm{Gst}=$ coefficient of gene differentiation or gene diversity among the population; $\mathrm{Nm}=\mathrm{level}$ of gene flow.

Table 6 Genetic diversity within 21 Nigerian Tuberculosis and Non Tuberculosis patients using inter-simple sequence repeat markers.

\begin{tabular}{|c|c|c|c|c|c|c|}
\hline Marker & $\mathbf{N a}$ & $\mathrm{Ne}$ & $\mathbf{H}$ & I & NPL & PPL\% \\
\hline ISSR 889 & 2.000 & $1.6598(0.197)$ & $0.3886(0.0791)$ & $0.5742(0.089)$ & 25 & 100 \\
\hline ISSR 827 & 2.000 & $1.8805(0.159)$ & $0.4637(0.0564)$ & $0.6551(0.061)$ & 25 & 100 \\
\hline ISSR 856 & 2.000 & $1.7712(0.289)$ & $0.4180(0.1113)$ & $0.6031(0.124)$ & 25 & 100 \\
\hline UBC 826 & 2.000 & $1.8443(0.194)$ & $0.0456(0.0712)$ & $0.6408(0.078)$ & 25 & 100 \\
\hline ISSR 888 & 2.000 & $1.9091(0.176)$ & $0.0472(0.0678)$ & $0.6611(0.075)$ & 25 & 100 \\
\hline ISSR 816 & 2.000 & $1.8659(0.191)$ & $0.4571(0.0707)$ & $0.6475(0.978)$ & 25 & 100 \\
\hline ISSR 890 & 2.000 & $0.7296(0.292)$ & $0.4016(0.1267)$ & $0.5807(0.580)$ & 24 & 96 \\
\hline ISSR 901 & $1.88(0.3317)$ & $1.5841(0.315)$ & $0.3396(0.1557)$ & $0.5016(0.213)$ & 22 & 88 \\
\hline ISSR 808 & $1.3200(0.47)$ & $1.1184(0.1895)$ & $0.0849(0.1301)$ & $0.1388(0.209)$ & 2 & 32 \\
\hline
\end{tabular}

Standard deviations are in parentheses; NPL=number of polymorphic loci; PPL=percentage polymorphic loci; $\mathrm{Ne}=$ effective number of alleles; $\mathrm{H}=\mathrm{Nei}$ 's gene diversity, I=Shannon's information index.

From the ten ISSR marker data, the number of polymorphic loci (NPL) and percentage polymorphic loci (PPL) ranged from $2-25$ and $32 \%-100 \%$, respectively as shown in Table 6. The Na, Ne, H and I spanned from 1.32002.0000, 1.1184-1.9091, 0.0456-0.4571 and 0.1388-0.6611, respectively. Their standard deviation ranges were 0.2000 $0.4761,0.1502-0.3154,0.0564-0.1557$ and $0.0615-0.9781$, respectively.

\subsection{Hierarchical Clustering TB and Non TB Population in Mile Four Hospital, Abakaliki}

A dendrogram of the $25 \mathrm{~TB}$ and NTB using UPGMA procedure clustered them into nine major groups (Figure 1). Group I consists of M4HP-11, M4HP-9, M4HP-10, M4HNP1 and M4HP-21, M4HP-19 with 40\% bootstrap value. They contained genotypes from places such as Ebonyi, Enugu, Anambra and Abia States. The genotype M4HP-19 is the most genetically isolated one in group I with genetic distance of $40 \%$. Group II had only M4HP-13 with $43 \%$ bootstrap value and it was collected from a patient from Ebonyi State. Group III clustered M4HP-20, M4HP-18, M4HP-16, M4HP17, M4HP-6, M4HP-5 with $38 \%$ bootstrap value and was collected from a patient from Enugu, Ebonyi and Abia State.
Group IV contained M4HNP-2, M4HP-3, M4HNP-3, M4HP7, M4HNP-4 and M4HP-14 with a bootstrap value of $41 \%$ and they were sampled from Anambra and Ebonyi States. Group V had $42 \%$ of genetic distance and clustered M4HP-1. Group VI had only M4HP-2 with a value of $47 \%$. Group VII clustered together M4HP-15 and M4HP-12 with a value of $45 \%$. Group VIII had a total of genetic distance of $49 \%$ and contained only M4HP- 8 . Group IX had a total of $50 \%$ of its genetic distance and clustered only M4HP-4. The dissimilarity maximum value was 0.7097 while that of the minimum was $3.5714 \times 10^{-2}$ at $95 \%$ percentile with the edge length sum of 3.0373 .

Principal component analysis of the generated amplicons resulted to five clusters (Figure 2). Each cluster is a representative of unique accession.

\section{Discussion}

The results of the study showed that six primers used were highly polymorphic. The six ISSR markers that were polymorphic in this study were in agreement with the work of Bonnet and Branchard on their work titled 'Non anchored Inter Simple Sequence Repeat Markers' they found out that ISSR 
markers were proved to be polymorphic in the assessment of genetic diversity [11]. The percentage of polymorphism observed among the study group was expected because the genotypes studied were from different individual that came from different States.

On the PIC value, most of the markers (seven) can be used as an informative in population - genetic analyses, this is in conformity with Botstein and his group on their works on the construction of a genetic - linkage map in man using restriction fragment length polymorphisms. According to them, the markers showing PIC values higher than 0.5 are normally considered as a good source of information in population genetics analyses [12]. The result of the population structure and genetic diversity showed that the mean values of total gene diversity $(\mathrm{Ht})$ was 0.4515 , that of gene diversity within population (Hs) was 0.3869 , coefficient of gene differentiation (Gst) or gene diversity among the population was 0.1580 and the level of gene flow $(\mathrm{Nm})$ was 2.6647. The high gene flow among populations detected in this study pointed towards the possibility of instances of more than one isolated populations possessing unique genotypes not found in other populations this is because Kumar and his group said that in population genetics, the value of gene flow was normally less than one migrant per generation into a generation, the value of GST among the population was greater than 0.25 and this generally was regarded as the threshold quantity beyond which significant population occurs [13]. The value of GST in this study was lower than that of the threshold quantity beyond which significant population occurs; this was in contrary with the work of Kumar on the assessment of genetic diversity of Podophyllumhexandrum using ISSR markers. In their study, The GST value was higher than that of the threshold quantity [13]. In assessing the population diversity of the study group, the ones from Enugu state demonstrated the highest values of $\mathrm{Ht}$ and Hs followed by those from Ebonyi state, and then Abia and lastly Anambra but GST was higher in the group from Abia state followed by Ebonyi State, Enugu and then Anambra. NM was higher in Ebonyi state followed by those from Enugu, then Abia and lastly Anambra state. The number of polymorphic loci (NPL) and percentage polymorphic loci (PPL) ranged from $2-25$ and $32 \%-100 \%$, respectively. The high level of percentage polymorphic loci (PPL) greater than $70 \%$ suggests that there was high degree of genetic variation among TB patients for ISSR marker, such high level of percentage polymorphic loci was also reported by Kumar and his group in their study on the assessment of genetic diversity of Podophyllumhexandrum using ISSR markers [13]. Their PPL were mostly $100 \%$ and few $80 \%$. The percentage polymorphism obtained from this present study was quite high indicating the higher informative nature of the ISSR markers used.

The number of observed alleles $(\mathrm{Na})$ is 2.0000 in all the samples tested. The maximum number of effective alleles (Ne) (1.9007) was found in population from Enugu and the lowest number $(0.8207)$ was detected in population from Anambra state. Based on the Nei's gene diversity $(\mathrm{H})$ and
Shannon's information index (I) values, Population from Anambra state showed a slightly lower genetic diversity. The analysis of genetic polymorphism obtain with ISSR markers demonstrated that the highest percentage of polymorphic loci (PPL) was $100 \%$, largest number of polymorphic loci (NPL) was 25 and the highest gene diversity $(\mathrm{H}=0.6363)$ and Shannon's information index (0.6668) were found in population from Enugu state. Therefore, the sample individuals from Enugu state could be considered to have the highest genetic diversity. This may be as a result of different strains of TB diseases among the patients.

Variation in the numbers of alleles at each marker locus serve as a measure of genetic variability. More than $80 \%$ of the markers exhibited three or more alleles per locus.

The effective number of allele at each locus provides information on predominant alleles. Since allelic diversity in this work was high, it can be concluded that the genetic diversity is sufficiently high. However, a higher number of alleles for each locus showed that the marker used were appropriate to analyze diversity.

The result of the dendrogram revealed that some of the clustering pattern of the groups showed the existence of definite pattern of relationship among TB patients, geographical origins and genetic diversity. It was obviously demonstrated that some groups were made up of only TB patients. Some clusters were made up of genotypes mostly from the same geographical region while others had genotypes from two or more areas, hence the number of entries varied from cluster to cluster. The clustering showed genetic relatedness among the individuals and the genetic distance varied among groups/clusters. The principal component analysis clustered them into five clusters with each cluster being so unique; four of the clusters are closely related and have genetic distance of 0.15 and below while one isolated itself and had a genetic distance of 0.5 . This divergence may have been caused by mutation or introduction of other materials in the person's body.

The NTB's clustering together with TB patients showed no variation between Non TB and TB patients, but the vast majority of the Non TB patients were grouped into a single group which indicates high similarity among the individuals.

In all, the presence of familial clustering with a genetic distance less than $50 \%$ in the dendrogram and 0.5 in the PCA shows that the TB patients though coming from different geographical locations are genetically related. The familiarity or closeness of the cluster indicates that there is a susceptibility gene somewhere in the chromosomal region.

Conclusively, this work has shown that this was the first known report on the use of ISSR markers for analyzing genetic diversity of people suffering from infectious diseases like TB, the result could not be compared with any other previous findings in Nigeria since none had been done to the best of my knowledge.

\section{Conclusion and Recommendation}

Based on the polymorphic feature and genetic diversity, it 
is evident from the data that since the allelic diversity is high, the genetic diversity is therefore high and based on the criterion for selecting ISSR markers, the markers used is highly polymorphic and it is very useful for the evaluation of genetic diversity within and among population. ISSRs have proved to be efficient in analyses of the levels of genetic differentiation and diversity in mammals and other organisms.

Also the clustering of both TB and Non TB patients in one cluster equally showed that the gene of an individual should not be considered as the main predisposing factor for susceptibility to TB disease.

Due to the limitations in the number of studied populations, further research with more population needs to be analysed to be able to evaluate the genetic diversity and population structure among populations.

\section{References}

[1] World Health Organization (2018). "World Tuberculosis Day" Global Tuberculosis report $287 \mathrm{pp}$.

[2] Davies, P. (2006). "A possible link between vitamin D deficiency and impaired host defense to Mycobacterium tuberculosis". Tubercle. 66 (4): 301-306.

[3] Anthony, H. (2005). TB/HIV: a Clinical Manual (seconded.). Geneva: World Health Organization. 75 pp.

[4] Möller, M. and Hoal, E. (March 2010). "Current findings, challenges and novel approaches in human genetic susceptibility to tuberculosis". Tuberculosis. 90 (2): 71-83.

[5] Nicas, M., Nazaroff, W. and Hubbard, A. (2005). "Toward understanding the risk of secondary airborne infection: emission of respirable pathogens". Journal of Occupational and Environmental Hygiene. 2 (3): 143-154.

[6] Restrepo, B. (2007)."Convergence of the tuberculosis and diabetes epidemics: renewal of old aquaintances". Clinical Infectious Diseases. 45 (4): 436-438.

[7] World Health Organization (2015). "Tuberculosis Factsheet" Global tuberculosis report Geneva: 104pp.

[8] World Health Organization (2016). "Tuberculosis Factsheet" Global Tuberculosis report Geneva 206 pp.

[9] World Health Organization (2015). World Health Organization international TB publication. Global Report $1126 \mathrm{pp}$.

[10] Houben, C. and Dodd, E. (2016) Burden of latent TB infections, A Re-estimation using Mathematical Modeling 45: 451-554.

[11] Bornet, B. and Branchard, M. (2012). 'Non anchored inter simple sequence repeat (ISSR) markers: Reproducible and specific tools for genome fingerprinting', Plant Molecular Biology Reporter 19; 209-215.

[12] Botstein D, (1980) Construction of a genetic-linkage map in man using restriction fragment length polymorphisms. American Journal of Human Genetics 32 (3): 314-31.

[13] Kumar, A., Gaura, G., Gandham, R., Panigrahi, M., Ghosh. S., Saravanan, B., Bhushan, B., Tiwari, A., Sulabh, S., Priya, B., Asaf, V., Gupta, J., Wani, S., Sahu, A. and Sahoo, A. (2017). Global gene expression profile of peripheral blood mono nuclear cells challenged Theileria annulata in cross bred and indigenous cattle. Infection, Genetics and Evolution; journal of molecular epidemiology and evolutionary genetics of infectious diseases 47: 9-18. 